\title{
RUMOS DA CRÍTICA GENÉTICA NO BRASIL
}

Philippe Willemart*

(iD) https://orcid.org/0000-0001-6370-4425

Edson do Prado Pfützenreuter ${ }^{\star \star}$

(iD) https://orcid.org/0000-0002-3331-3420

Cecilia Salles***

(iD) https://orcid.org/0000-0003-3826-0142

Claudia Amigo Pino ${ }^{* * *}$

(iD) https://orcid.org/0000-0001-7311-316X

Como citar este artigo: WILLEMART, P. et al. Rumos da crítica genética no Brasil. Todas as Letras - Revista de Lingua e Literatura, São Paulo, v. 23, n. 1, p. 1-20, jan./abr. 2021. DOI 10.5935/1980-6914/eLETDO2114255

Submissão: janeiro de 2021. Aceite: fevereiro de 2021.

Resumo: O artigo, escrito em colaboração com vários membros da Associação dos Pesquisadores em Crítica Genética (APCG), esboça o panorama atual dos estudos de gênese no Brasil e constata a abrangência do objeto de estudo não mais limitado ao estudo do manuscrito ou dos esboços dos artistas, mas estendendo-se a qualquer atividade humana que implique processos de criação ou documentos de processo.

Palavras-chave: APCG. Processos de criação. Documento de processo. Crítica genética. Artes.

\footnotetext{
* Universidade de São Paulo (USP), São Paulo, SP, Brasil. E-mail: plmgwill@gmail.com

** Universidade Estadual de Campinas (Unicamp), Campinas, SP, Brasil. E-mail: reuter@unicamp.br

*** Pontifícia Universidade Católica de São Paulo (PUC-SP), São Paulo, SP, Brasil. E-mail: cecilia.salles@gmail.com

**** Universidade de São Paulo (USP), São Paulo, SP, Brasil. E-mail: camigopino@gmail.com
} 
DOSSIE

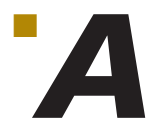

ntes de iniciar a apresentação do artigo, gostaria de lembrar como entendo a relação dos estudos de gênese com a filologia dita antiga ou nova.

Se o objeto da filologia continua sendo o estabelecimento da melhor lição e o objeto da crítica genética - a detecção dos processos de criação ou o estudo dos documentos de processos -, a finalidade de ambos parecia ser auxiliar à interpretação do texto editado (WILLEMART, 1999, p. 202). No entanto, no que se refere à crítica genética, o objeto e a finalidade mudaram nos últimos anos, como a apresentação das diferentes tendências a seguir mostrará ao leitor.

A crítica genética não se limita mais a pesquisar o texto literário, mas abrange todos os campos em que intervenha a criação de novos objetos, seja a arte, seja uma mensagem no WhatsApp, seja uma emissão de televisão. A finalidade ultrapassa a interpretação do produto final (texto, quadro, melodia, escultura etc.) e pode até ser a comparação com os processos usados pela inteligência artificial ou pelos mecanismos do cérebro. Isto é, a crítica genética do século XX não é mais a do século XXI.

O artigo reúne contribuições de vários membros da Associação dos Pesquisadores em Crítica Genética (APCG), que comporta mais de 150 pesquisadores no Brasil e edita a revista bianual Manuscritica ${ }^{1}$.

Fundada em 1985, no primeiro congresso, com o nome de Associação dos Pesquisadores do Manuscrito Literário (APML), tendo como foco apenas os manuscritos referentes à literatura, a APML, sob a ação de vários membros liderados por Cecília Almeida Salles, da Pontificia Universidade Católica de São Paulo (PUC-SP), ampliou seu campo de pesquisa desde 1990, incluindo os trabalhos e esboços dos artistas e das mídias, e denominou-se APCG, considerando a literatura uma das suas linhas de pesquisa.

Seguem as colaborações de quatro membros da APCG:

1. Edson de Prado Pfützenreuter, do Instituto de Artes da Universidade Estadual de Campinas (Unicamp) e atual presidente da APCG, fez o levantamento dos artigos da Manuscrítica de 2015 até hoje e dos participantes dos dois últimos congressos de Ouro Preto e de Curitiba.

2. Cecília Almeida Salles salienta a originalidade da pesquisa no seu grupo da PUC-SP.

3. Claudia Consuelo Pino, da Faculdade de Filosofia, Letras e Ciências Humanas da Universidade de São Paulo (FFLCH-USP), detalhou o teor e a ação de três grupos: o Nuproc, liderado por Sergio Romanelli (Universidade Federal de Santa Catarina - UFSC), que estuda as traduções do imperador Pedro II; o de Epistolografia, liderado por Marcos Morais (Instituto de Estudos Brasileiros -IEB-USP); e o dos pesquisadores da FFLCH sobre romances de lingua francesa.

4. Philippe Willemart destaca a ação de outros grupos. 


\title{
RETRATO NUMÉRICO DA CRÍtICA GENÉTICA NO BRASIL
}

\author{
Edson de Prado Pfützenreuter
}

Estatística: a ciência que diz que se eu comi um frango e tu não comeste nenhum, teremos comido, em média, meio frango cada um. Dino Segrè (Pitigrilli)

Ao pensar no panorama da crítica genética, deve-se lembrar que já foram feitos levantamentos importantes no passado, como aquele desenvolvido por Willemart (2009, p. 79-89), que traz um histórico e busca identificar quem desenvolve esse tipo de pesquisa no Brasil, elencando congressos e grupos de pesquisa, abordando também as publicações que existiam até 2008.

Há, ainda, o trabalho feito por Romanelli, que, na introdução de seu livro, busca mapear a atuação da crítica genética na América Latina a partir de um encontro organizado em 2013. Ele retoma a criação dessa abordagem de pesquisa no Brasil, lembrando que:

O núcleo gerador desse processo de instituição da Crítica Genética no Brasil foi a publicação no Folhetim de São Paulo do dia 29 de abril de 1984 do artigo "O prototexto: edição crítica e gênese do texto", de autoria de Philippe Willemart (ROMANELLI, 2019, p. 10).

Romanelli comenta as discussões provocadas por esse artigo e a continuidade dessa forma de pesquisa, que se desenvolveu gerando grupos de investigação em universidades diferentes. O artigo apresenta um levantamento desses diversos núcleos que estão de alguma maneira relacionados com a pesquisa em crítica genética. Esse trabalho até hoje é muito importante, uma vez que esses grupos continuam atuantes.

Essa contribuição para o estabelecimento de um retrato da crítica genética no Brasil está voltada para o levantamento dos artigos publicados na revista Manuscrítica, assim como os artigos encaminhados para o congresso da APCG.

Uma vez que o levantamento feito por Sérgio Romanelli abordava o que havia sido desenvolvido até 2013, decidiu-se abordar as revistas publicadas desde aquele ano, do número 24 ao 40, esse editado em 2020.

Nessa catalogação foram enfatizados os artigos, excluindo-se os editoriais e as seções "Passado a limpo", que contêm notícias e eventos relacionados à crítica genética.

O procedimento consistiu em elaborar uma tabela com os seguintes dados: ano de publicação, número da revista, o dossiê da revista (caso houvesse), títulos dos artigos, autores, universidades, departamentos e palavras-chave.

A planilha facilitou o trabalho de análise e obtenção de dados numéricos referentes à revista, os quais oferecem informações relevantes para o estabelecimento de um panorama. O tratamento numérico foi feito com funções da planilha em que a tabela foi colocada, mas também foram utilizadas ferramentas oferecidas no site linguakit.com. Todos os dados mostrados aqui foram obtidos a partir das informações disponiveis no site da revista Manuscrítica e foram compilados pelo autor do artigo. 
DOSSIÊ

O primeiro resultado numérico, mostrado na Tabela 1, evidencia que durante esse período foram publicados 17 números da revista. De 2013 a 2017, foram publicados dois números por ano e, em 2018, começaram a ser publicados três números por ano.

O aumento dos números anuais da revista está relacionado à busca por uma melhor qualificação no Qualis-Capes, mas também indica um aumento na produção de pesquisa nessa área. Isso aparece ainda em outros dados que serão mostrados a seguir.

A produção veiculada nessas revistas abrange um total de 268 artigos, sendo que as edições não apresentam o mesmo número de artigos, variando de 9 a 21 , o que resulta em uma média de 16 artigos por número.

As tabelas funcionam como signo do que é a revista e, como todo signo, destacam alguns elementos e permitem a construção de alguma generalidade.

Esse conjunto aponta que 268 pessoas publicaram na revista Manuscritica. O número é maior do que o total de artigos, pois existem alguns com mais de uma autoria. Desse total, há 170 autoras (mulheres) e 98 autores (homens).

Tabela 1 - Artigos publicados na revista Manuscrítica

\begin{tabular}{|c|c|c|c|c|c|c|}
\hline Ano & $\mathbf{N}^{\circ}$ & Dossiê & $\begin{array}{l}\text { Artigos } \\
\text { publicados }\end{array}$ & Autores & Autoras & $\begin{array}{l}\text { Total de } \\
\text { autoria } \\
\text { de artigos }\end{array}$ \\
\hline 2013 & 24 & $\begin{array}{l}\text { A critica genética na América do } \\
\text { Sul: pesquisas e perspectivas }\end{array}$ & 24 & 14 & 12 & 26 \\
\hline 2013 & 25 & Poesia: o texto em movimento & 25 & 13 & 13 & 26 \\
\hline 2014 & 26 & $\begin{array}{l}\text { Não houve título de dossiê nessa } \\
\text { edição }\end{array}$ & 26 & 3 & 9 & 12 \\
\hline 2014 & 27 & Crítica genética comparada & 27 & 4 & 11 & 15 \\
\hline 2015 & 28 & Samuel Beckett & 28 & 4 & 8 & 12 \\
\hline 2015 & 29 & $\begin{array}{l}\text { Não houve título de dossiê nessa } \\
\text { edição }\end{array}$ & 29 & 3 & 9 & 12 \\
\hline 2016 & 30 & $\begin{array}{l}\text { Como criar junto: bibliotecas e } \\
\text { coleções }\end{array}$ & 30 & 3 & 9 & 12 \\
\hline 2016 & 31 & Arquivos contemporâneos & 31 & 5 & 13 & 18 \\
\hline 2017 & 32 & Crítica genética no Nordeste & 32 & 6 & 8 & 14 \\
\hline 2017 & 33 & Cadernos de criação & 33 & 5 & 11 & 16 \\
\hline 2018 & 34 & $\begin{array}{l}\text { A criação em circulação 1: artes } \\
\text { visuais e performáticas }\end{array}$ & 34 & 4 & 13 & 17 \\
\hline 2018 & 35 & $\begin{array}{l}\text { A criação em circulação } 2: \text { da } \\
\text { correspondência de escritores } \\
\text { às edições }\end{array}$ & 35 & 6 & 10 & 16 \\
\hline
\end{tabular}

(continua) 
Tabela 1 - Artigos publicados na revista Manuscrítica (conclusão)

\begin{tabular}{|l|c|l|c|c|c|c|}
\hline Ano & $\mathbf{N}^{\mathbf{0}}$ & \multicolumn{1}{|c|}{ Dossiê } & $\begin{array}{c}\text { Artigos } \\
\text { publicados }\end{array}$ & Autores & Autoras & $\begin{array}{c}\text { Total de } \\
\text { autoria } \\
\text { de artigos }\end{array}$ \\
\hline 2018 & 36 & $\begin{array}{l}\text { A criação em circulação 3: a } \\
\text { criação literária }\end{array}$ & 36 & 9 & 7 & 16 \\
\hline 2019 & 37 & $\begin{array}{l}\text { Processos de criação do livro } \\
\text { para a infância: imagem, palavra } \\
\text { e construção poética }\end{array}$ & 37 & 2 & 18 & 20 \\
\hline 2019 & 38 & $\begin{array}{l}\text { Não houve título de dossiê nessa } \\
\text { edição }\end{array}$ & 38 & 2 & 7 & 9 \\
\hline 2019 & 39 & $\begin{array}{l}\text { Não houve título de dossiê nessa } \\
\text { edição }\end{array}$ & 39 & 7 & 4 & 11 \\
\hline 2020 & 40 & Rascunhos do contemporâneo I & 40 & 8 & 8 & 16 \\
\hline \multicolumn{2}{|l}{ Total de autoria de artigos } & & 98 & 170 & 268 \\
\hline \multicolumn{2}{l}{ Média por número da revista } & 5 & 9 & 16 \\
\hline
\end{tabular}

Fonte: Elaborada pelos autores.

Contamos artigos escritos por representantes de 71 instituições diferentes e, desse total, houve colaborações de 16 universidades estrangeiras. Na Tabela 2, foram listadas as instituições cujos pesquisadores e pesquisadoras participaram com pelo menos dez publicações ${ }^{2}$.

Tabela 2 - Instituições que publicaram na revista

\begin{tabular}{|l|l|c|}
\hline \multicolumn{1}{|c|}{ Universidade } & \multicolumn{1}{c|}{ Região } & Participação \\
\hline Universidade de São Paulo & Sudeste & 63 \\
\hline Universidade Federal de Santa Catarina & Sul & 23 \\
\hline Universidade Estadual de Campinas & Sudeste & 20 \\
\hline Antwerp University & Internacional & 14 \\
\hline Universidade Federal da Bahia & Nordeste & 14 \\
\hline Universidade Estadual Paulista “Júlio de Mesquita Filho” & Sudeste & 11 \\
\hline Pontifícia Universidade Católica de São Paulo & Sudeste & 10 \\
\hline
\end{tabular}

Pode-se perceber uma grande variedade de instituições - universidades, institutos de pesquisa e bibliotecas - que colaboraram com a revista, evidenciando sua amplitude e também sua internacionalização, que desde o início foi um objetivo da APCG. Esse dado fica mais evidente na visualização da tabela completa.

2 Os dados detalhados de todas as tabelas estão disponíveis em: https://docs.google.com/spreadsheets/d/1TtHMMRMdz-fl7LYHIwr RERk_CQqG9d3-kwfuEA0BKIw/edit?usp=sharing 
DOSSIE

Considerou-se importante avaliar a distribuição da participação de universidades pelas regiões do Brasil (Tabela 3). O resultado obtido poderia ter sido previsto em função da história da educação de nivel superior no país, com a distribuição desigual das universidades e dos cursos de graduação e pós-graduação.

Tabela 3 - Total de artigos por região

\begin{tabular}{|l|c|c|c|c|c|c|}
\hline & Brasil & Sul & Sudeste & Norte & Nordeste & Cento-Oeste \\
\hline Total & 217 & 54 & 132 & 7 & 23 & 1 \\
\hline Total (\%) & $100,00 \%$ & $24,90 \%$ & $60,80 \%$ & $3,20 \%$ & $10,60 \%$ & $0,50 \%$ \\
\hline
\end{tabular}

Para ter uma ideia geral dos assuntos tratados na revista, a lista total de palavras-chave utilizadas foi submetida a uma análise multiword extraction no site Linguakit ${ }^{3}$. Seu funcionamento é explicado em termos computacionais no artigo de Gamallo et al. (2018). Num sistema de natural language processing (NLP), a operação busca os termos mais relevantes, comparando com várias bases lexicais, atribuindo a cada expressão um peso estatístico que é o resultado do cálculo feito nessa operação.

As palavras-chave mais destacadas nessa análise foram crítica genética, processo de criação, arte contemporânea, literatura brasileira e arquivos de criação. Esses dados podem ser vistos parcialmente na Tabela 4, ou de forma visual na nuvem de palavras (Figura 1).

Tabela 4 - Análise da ocorrêcia de palavras-chave nos artigos da revista

\begin{tabular}{|l|l|}
\hline Peso & \multicolumn{1}{|c|}{ Palavra-chave } \\
\hline 74.371 & Crítica genética \\
\hline 41.064 & Crítica genética \\
\hline 30.572 & Processo de criação \\
\hline 13.312 & Processo de criação \\
\hline 9.930 & Folha de contato \\
\hline 7.925 & Parnasianismo Marginália \\
\hline 7.925 & Gustave Flaubert \\
\hline 7.280 & Processos de criação \\
\hline 6.901 & Roland Barthes Seminários \\
\hline 6.687 & Manuscrito moderno \\
\hline & \\
\hline
\end{tabular}


Figura 1 - Nuvem de palavras baseada nas palavras-chave dos artigos

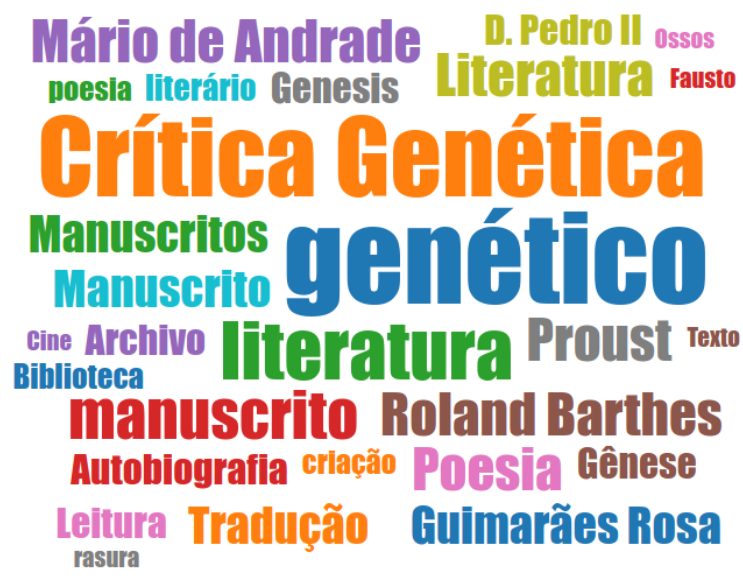

Fonte: Elaborada pelos autores.

Foi feito também um levantamento de palavras repetidas nos resumos com a intenção de identificar os tipos de manifestação artística que são estudados nos artigos publicados. O resultado pode ser visto na Tabela 5.

Tabela 5 - Número de ocorrências de palavras na totalidade dos artigos

\begin{tabular}{|l|c|}
\hline \multicolumn{1}{|c|}{ Palavra } & Número de ocorrências \\
\hline Arte & 56 \\
\hline Literatura & 47 \\
\hline Teatro & 14 \\
\hline Dança & 9 \\
\hline Fotografia & 7 \\
\hline Pintura & 6 \\
\hline Cinema & 4 \\
\hline Design & 4 \\
\hline Música & 4 \\
\hline Vídeo & 2 \\
\hline Artes visuais & 1 \\
\hline
\end{tabular}

Fonte: Elaborada pelos autores.

A organização dos dados destaca alguns aspectos, permitindo a construção de alguma generalidade. Além da conclusão que já citamos a respeito da amplitude e da internacionalização da revista, também se torna evidente que a crítica genética é uma área já estabelecida e que a revista Manuscrítica teve um papel importante no estabelecimento dessa área. 
DOSSIÊ

Existe uma predominância dos trabalhos em crítica genética na USP, fato explicável em função de ali ter sido a origem desses estudos no Brasil. No entanto, percebe-se uma grande quantidade de universidades participando de estudos dessa área.

O levantamento das palavras-chave não permite determinar com clareza as diversas áreas que estão sendo estudadas. Por outro lado, a leitura dos resumos deixa clara uma predominância da área de literatura. Contudo, ao contarmos a ocorrência de palavras nos resumos, existe uma predominância da palavra arte e uma presença grande de outras manifestações artísticas, indicando outras áreas que estão sendo estudadas, ressaltando a diversidade de pesquisas.

Existe uma margem de erro nos dados obtidos, pois algumas informações não constavam no site da revista. Tivemos também o caso de informações iguais que foram declaradas pelos autores de maneiras diferentes, por exemplo: Universidade Federal de Santa Catarina e UFSC. Nesse caso, o cálculo considera como duas universidades diferentes; para evitar esse problema, foram feitas uma revisão e uma padronização dos nomes de universidades. Esse fato também ocorreu com os nomes de autores e autoras.

A observação da tabela com todos os arquivos permite verificar que não há muita repetição de universidades e de autores de uma revista para outra, indicando que esse seria um dos fatores a colaborar com a diversidade de assuntos de rodagem.

\section{Dados dos congressos}

A APCG promove a cada dois anos um congresso de abrangência internacional. Neste artigo serão abordados os dados de referência a três congressos:

1. XII Congresso Internacional da APCG

Tema: Estudos de processo no século XXI: multilinguismo, multimídia e multiverso.

10 a 12 de outubro de 2015 - Universidade Federal da Bahia (Ufba)

2. XIII Congresso Internacional da APCG

Tema: Criação em circulação

18 a 20 de outubro de 2017 - Universidade Federal de Ouro Preto (Ufop)

3. XIV Congresso Internacional da APCG

Tema: Rascunhos do contemporâneo

12 e 13 de outubro de 2019 - Universidade Federal do Paraná (UFPR)

O procedimento adotado na análise foi similar ao utilizado em relação à revista, com a diferença de que, afinal, não estamos lidando com os artigos, mas com resumos publicados no caderno de resumos do congresso. 
Tabela 6 - Temas dos congressos

\begin{tabular}{|c|c|l|c|c|c|c|}
\hline Ano & $\mathbf{N}^{\mathbf{0}}$ & \multicolumn{1}{|c|}{ Tema } & Resumos & Autores & Autoras & $\begin{array}{c}\text { Total } \\
\text { (autoria) }\end{array}$ \\
\hline 2015 & 12 & $\begin{array}{l}\text { Estudos do processo no } \\
\text { século XXI: multilinguismo, } \\
\text { multimídia e multiverso }\end{array}$ & 110 & 33 & 96 & 129 \\
\hline 2017 & 13 & Criação em circulação & 118 & 56 & 76 & 132 \\
\hline 2019 & 14 & Rascunhos do contemporâneo & 76 & 35 & 54 & 89 \\
\hline Total & & & 304 & 113 & 196 & 309 \\
\hline
\end{tabular}

Um olhar sobre a Tabela 6 evidencia que houve uma boa participação nos congressos de 2015 e 2017 e uma queda na edição de 2019. Muito provavelmente isso está relacionado com as questões econômicas e os cortes de verba para pesquisa. Seguindo uma tendência que já havia aparecido na revista, podemos identificar a predominância de mulheres pesquisadoras em relação à quantidade de homens que desenvolvem esse tipo de pesquisa.

Nos três congressos tivemos uma participação de 66 universidades, sendo sete internacionais. Embora seja um bom indice, evidencia-se que a participação internacional nos congressos é inferior à participação nas revistas. Também merece destaque a grande participação de membros da Ufba - provavelmente em função de o $12^{\circ}$ Congresso ter ocorrido naquela universidade. A Tabela 7 mostra a totalidade dos resumos enviados pelas universidades que enviaram ao menos 15 propostas de comunicação ${ }^{4}$.

Tabela 7 - Universidades participantes

\begin{tabular}{|l|c|}
\hline \multicolumn{1}{|c|}{ Universidade } & Total de resumos \\
\hline Universidade Federal da Bahia & 69 \\
\hline Universidade de São Paulo & 56 \\
\hline Pontifícia Universidade Católica de São Paulo & 29 \\
\hline Universidade Estadual do Piauí & 27 \\
\hline Universidade Federal de Santa Catarina & 22 \\
\hline Universidade Federal do Espírito Santo & 22 \\
\hline Universidade Estadual de Campinas & 17 \\
\hline Universidade Federal do Paraná & 15 \\
\hline
\end{tabular}

Fonte: Elaborada pelos autores.

\footnotetext{
4 Os dados detalhados de todas as tabelas estão disponíveis em: https://docs.google.com/spreadsheets/d/1hAw5-tnopBb-loKCEUzA --vJx64wNGf_OfM2O6hh8/edit?usp=sharing.
} 
DOSSIE

A totalidade de participação nos congressos é de 309 pesquisadores(as), sendo que somente nove participantes são extrangeiros. A Tabela 8 mostra a distribuição dos(as) autores(as) brasileiros(as) por região. Encontramos nessa tabela um resultado similar ao da revista, talvez pelas mesmas razões relacionadas ao desenvolvimento desigual do país.

Tabela 8 - Percentagem de participantes por região

\begin{tabular}{|l|c|c|c|c|c|c|}
\hline & Brasil & Sul & Sudeste & Norte & Nordeste & Cento-Oeste \\
\hline Total & 300 & 53 & 146 & 15 & 69 & 4 \\
\hline Total (\%) & $100 \%$ & $18 \%$ & $48,67 \%$ & $5 \%$ & $23,33 \%$ & $5 \%$ \\
\hline
\end{tabular}

Fonte: Elaborada pelos autores.

A verificação das palavras-chave e dos resumos permite estabelecer o que está sendo pesquisado. O procedimento foi o mesmo adotado em relação à revista, utilizando a análise multiword extraction no site Linguakit. O resultado obtido é mostrado parcialmente na Tabela 9, assim como no mapa de trabalho na nuvem de palavras (Figura 2).

Tabela 9 - Análise da ocorrência de palavras-chave nos resumos de congressos

\begin{tabular}{|l|l|}
\hline Peso & \multicolumn{1}{c|}{ Palavra } \\
\hline 111.454 & Crítica genética \\
\hline 105.426 & Processo de criação \\
\hline 33.769 & Processo criativo \\
\hline 29.296 & Crítica genética \\
\hline 22.604 & Processo de criação \\
\hline 21.411 & Texto teatral \\
\hline 11.46 & Edição genética \\
\hline 11.16 & Documentos de processo \\
\hline 10.403 & Peça radiofônica \\
\hline 10.403 & Ensino de design \\
\hline
\end{tabular}

Fonte: Elaborada pelos autores. 
Figura 2 - Nuvem de palavras baseada nas palavras-chave dos resumos

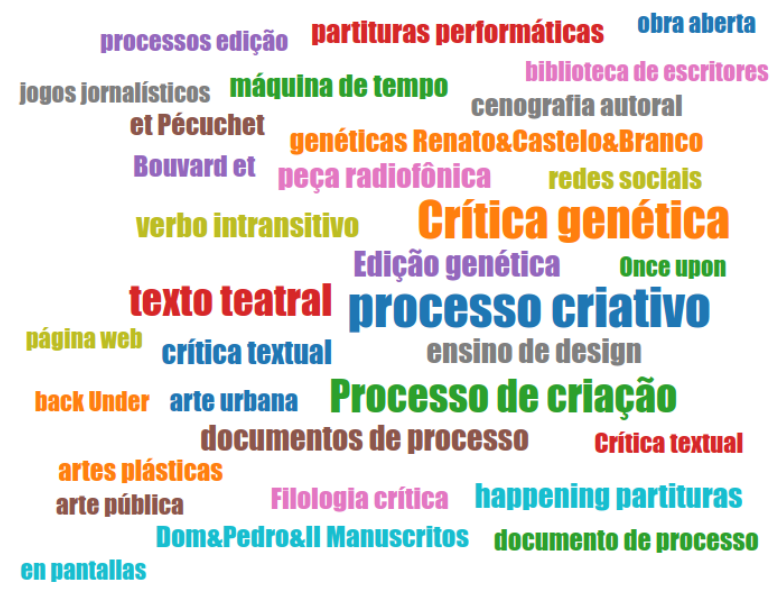

Fonte: Elaborada pelos autores.

Com relação aos resumos, procurou-se o número de ocorrência de algumas palavras importantes para identificar as linguagems artísticas quem têm sido estudadas. O resultado está na Tabela 10.

Tabela 10 - Número de ocorrências de palavras na totalidade dos resumos

\begin{tabular}{|l|c|}
\hline \multicolumn{1}{|c|}{ Palavra } & Número de ocorrências \\
\hline Arte & 193 \\
\hline Literatura & 55 \\
\hline Design & 41 \\
\hline Fotografia & 38 \\
\hline Poesia & 28 \\
\hline Cinema & 25 \\
\hline Teatro & 23 \\
\hline Palavra & 18 \\
\hline Desenho & 17 \\
\hline Vídeo & 17 \\
\hline Dança & 16 \\
\hline Pintura & 16 \\
\hline Música & 10 \\
\hline Artes visuais & 3 \\
\hline
\end{tabular}

Fonte: Elaborada pelos autores. 
O título dado a essa seção utiliza a metáfora do retrato. Continuando essa metáfora, temos um retrato que deixa detalhes de fora e talvez tenha algumas partes desfocadas, mas permite uma visão geral do que tem acontecido nessa área de estudos de genética criativa.

\section{Grupo de Estudos em Processos de Criação}

\section{Cecília Almeida Salles}

A história das pesquisas sobre processos de criação na PUC-SP teve seu início nos anos de 1990, a partir de um doutorado em Literatura Brasileira Contemporânea, mais especificamente, sobre Ignácio de Loyola Brandão. Trata-se de um percurso de expansão, sob diferentes perspectivas.

O grupo de pesquisa, formado em 1993, logo acolheu estudos em diversas áreas, como artes visuais, cinema, artes cênicas, literatura, arquitetura, design, fotografia, música, jornalismo, curadoria e crítica. Uma grande diversidade de documentos analógicos e/ou digitais do percurso, ou seja, arquivos da criação, são estudados como índices do pensamento em criação.

Nos inúmeros estudos de caso foram observadas recorrências ou aspectos gerais da criação, que passaram a guiar a sistematização de uma teoria crítica de processos (SALLES, 2008; 2011), que vem discutindo a criação como rede em construção, em diálogo com a semiótica peirceana, o conceito de rede de Pierre Musso e o pensamento da complexidade de Edgar Morin.

À medida que uma possivel teoria da criação é configurada, há uma inversão de perspectiva: os estudos sobre as histórias de obras específicas, característicos da crítica genética, passaram a estar a serviço de algo mais amplo, que é a teorização sobre o processo criador. A teorização passou a ser mais geral do que a metodologia, que passou a conviver com outros procedimentos metodológicos.

Os processos em grupo passaram a ser estudados a partir de documentos como diários de atores, cartas de diretor para montadores de filmes e registros audiovisuais de percursos de criação das artes cênicas, só para citar alguns exemplos (SALLES, 2017). Nesse contexto das equipes, abriu-se a possibilidade também de fazer o acompanhamento de processo, ampliando assim a metodologia para além do acesso a arquivos das histórias das obras.

Processo de criação passa, assim, a ser um tema transversal a diferentes áreas, pensando em seus desdobramentos para além das artes, por exemplo, no jornalismo, na educação e na ciência.

\section{Novos intercâmbios}

Nesses últimos anos, houve uma ampliação dos intercâmbios com pesquisadores interessados em processos de criação. Para citar alguns no campo do audiovisual, há o Centro de Investigação em Artes e Comunicação (Ciac), da Universidade do Algarve, sob a coordenação de Miriam Tavares; os pesquisadores sobre Materialidades dos Processos de Criação no Cinema Português, como Caterina Cucinotta; e os estudiosos da Teoria de Cineastas como Manuela Penafria e Eduardo Baggio. Já no campo da criação teatral, houve o congresso Tracing creation: genetics, genes and genealogies of performance, que aconteceu na Antuérpia, Bélgica, em 2016, liderado por Luk van den Dries. 


\section{Tendências de pesquisas}

Os estudos sobre artistas específicos continuam a ser desenvolvidos no Grupo de Estudos em Processos de Criação, da PUC-SP, caminhando lado a lado com novas interações, como com o educativo nos museus, processos de criação da cultura - mais especificamente, a Folia de Reis em Uberlândia -, além do estabelecimento de relações entre arte e ciência. Por outro lado, a ampliação dos diálogos teóricos gerou pesquisas que adensam as discussões da criação como rede com o olhar da psicanálise.

Pode-se observar também um novo caminho de pesquisas desenvolvidas por artistas/pesquisadores que encontram no grupo e na critica de processo um lugar para reflexão de suas práticas artísticas.

Outro espaço de expansão dessas pesquisas é a estreita relação com a experimentação contemporânea. Nesse contexto, a teorização sobre os processos criativos possibilitou discutirmos outros objetos e questões processuais, que extravasam os limites das histórias das obras.

Só para citar um exemplo, fui convidada para participar do projeto "Aesthesis: a criação em fluxo" (RUMOS ITAÚ CULTURAL, 2015). Os membros do grupo, que moravam em cidades distantes, fizeram registros do percurso por diferentes meios, como WhatsApp, vídeos e fotografias. No momento de tornar o projeto público, esses documentos coletivos foram levados para um espaço expositivo/ performático.

Esta foi a minha reação, enviada posteriormente ao grupo:

O convite para a minha participação foi bastante motivador, por não saber exatamente como seria meu envolvimento. Ao começar a acompanhar as atividades e entrar no espaço de ação do grupo, o que mais me atraiu foi o modo como eles tinham conseguido dar tridimensionalidade para as camadas do processo de criação. As paredes como suporte de registros audiovisuais, justaposição de anotações, livros consultados (e por nós consultáveis) explicitavam a proposta. Além disso, houve a sedutora leitura dramática das mensagens por WhatsApp, que nos colocaram na duvidosa certeza de estar vivendo o tempo do processo. Muito dificil de avaliar a minha participação; mas, sob o meu ponto de vista, me senti à vontade nesse ambiente no qual as fronteiras entre processo e espetáculo apresentado publicamente se diluem.

Refiro-me ao ambiente com o qual o crítico de processo convive.

Expor-se à experimentação contemporânea é conviver, entre muitas outras coisas, com diferentes relações entre processo e obra e exploração de arquivos, que, em alguns projetos artísticos, deixam de pertencer ao passado das obras e passam a ser mostrados ao público. Falam de um processo não mais particular e íntimo. Não se pode deixar de destacar também o amplo uso de diferentes plataformas, como Facebook, Instagram, TikTok, mostrando obras processuais, lives e registros de processo, especialmente nesse contexto da pandemia em que vivemos.

O grupo de pesquisa segue, assim, na tentativa de enfrentar algumas provocações artísticas que envolvem a complexidade que os arquivos de criação ganharam nessas últimas décadas, oferecendo uma abordagem crítica de processo. 


\section{UM OLHAR HISTÓRICO PARA A TRADUÇÃo}

\section{Claudia Amigo Pino}

Liderado por Sergio Romanelli, o Núcleo de Estudos do Processo de Criação (Nuproc), da UFSC, é muito mais recente que o que da PUC-SP. O grupo está engajado desde 2016 em um projeto que visa fazer uma edição genética digital dos manuscritos de tradução e do diário de D. Pedro II, o Imperador do Brasil entre 1831 e 1889.

Em crítica genética, estamos acostumados a trabalhar com corpus de escritores conhecidos, publicados e comentados pela crítica. É rato ver estudos sobre as tentativas literárias de homens da politica, mas o interesse em estudar os documentos de D. Pedro excede muito sua perspectiva literária: ele também foi responsável pelas relações culturais entre Brasil e Europa, enviando poetas brasileiros para estágios, apoiando suas publicações e traduções de ambos os lados e fazendo estudos críticos de tradução comparada.

O projeto não se limita à construção do perfil, das ideias e das atividades tradutórias do imperador, mas o estudo da rede de contatos que ele tinha com intelectuais importantes de diversas culturas. Por meio do exame de traduções conservadas nos arquivos no Brasil, tentamos reconstituir a rede complexa de contatos e a compreender o impacto dessas mudanças sobre a construção de uma identidade brasileira (ROMANELLI; STALLAERT; SOARES; MAFRA, 2018, p. 1).

Ele traduzia principalmente poetas que admirava - Victor Hugo, Longfellow, Manzoni, Schiller, Liégeard, Homer, Lamartine - do francês e inglês, mas também desenvolveu projetos muito mais intrépidos, como a tradução de As mil e uma noites, do árabe; Hitopadesha, do sânscrito; e A divina comédia, do latim. Durante sua vida, publicou apenas três traduções: Prométhée enchaîné, de Ésquilo; seleções de poemas (incluindo "A borboleta e a flor", de Victor Hugo) e Poesia Hebraica Provençal do Ritual Israelita Comtadin. Já se estudaram suas obras, mas essa é a primeira vez que se trabalha com seus manuscritos preparatórios, suas traduções inéditas e seus diários, que nos permitem conhecer as motivações políticas das escolhas de D. Pedro e o sistema cultural que ele ajudou a construir.

Em colaboração com a Universidade da Antuérpia, esse vasto projeto propõe a publicação de edições genéticas digitais, além de textos críticos para discutir o contexto e o processo de criação das traduções. Esse trabalho de publicação já começou, é possivel consultar a publicação genética do Hitopadesha no site: http://www.nuproc.cce.ufsc.br/. 

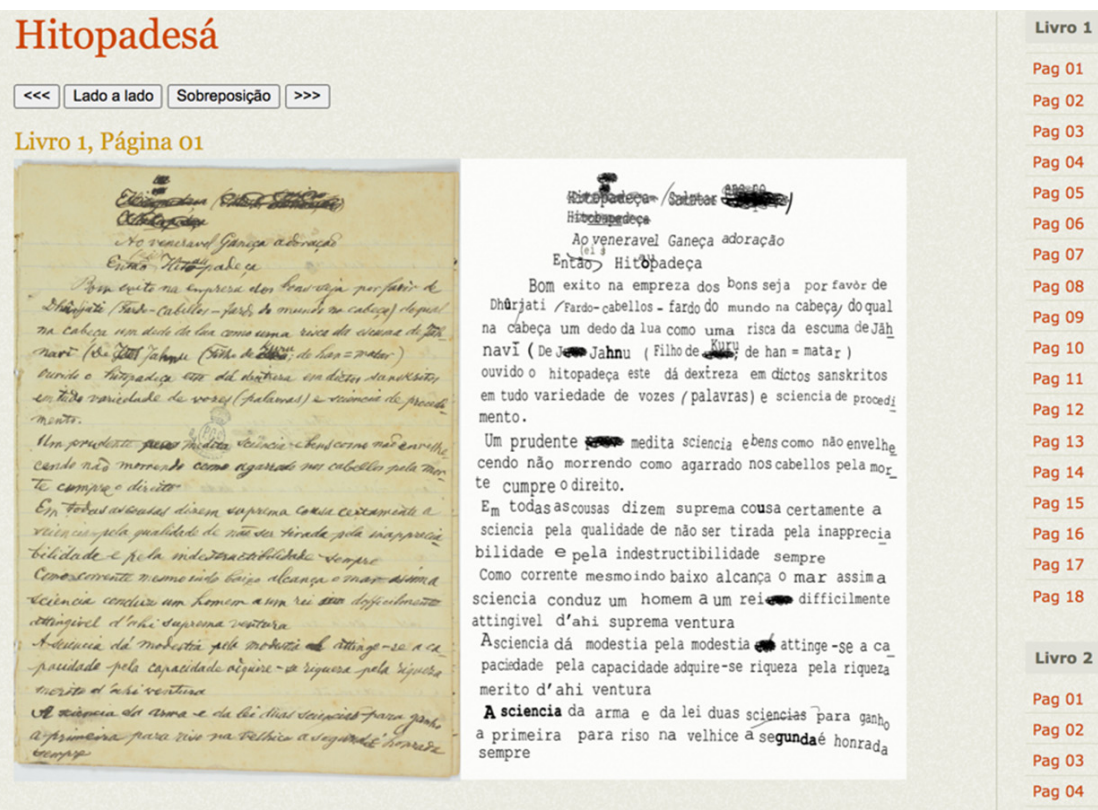

Fonte: Nuproc (2020).

\section{Artífices da correspondência}

Mais conhecido pelos geneticistas que trabalham em autobiografias, o grupo de pesquisa em epistolografia, liderado por Marcos Moraes, da Universidade de São Paulo (USP), iniciou essas atividades nos anos 2000. À época, o grupo se concentrou nas cartas de Mário de Andrade, que recebeu diversos projetos e rascunhos de outros escritores contemporâneos dele, o que aproximou esse grupo da genética. Com o apoio de um projeto da USP/Cofecub com a Universidade de Paris III, de 2013 a 2016, o grupo se dedicou a um grande trabalho de recuperação e publicação de correspondências brasileiras, especialmente as de escritores que tinham correspondentes franceses.

Esse projeto, naturalmente, produziu edições de livros e artigos, mas também seminários e cursos (na França e no Brasil) em torno da publicação e tradução de trabalhos franceses sobre correspondência, como o texto de Alain Pagès sobre materialidade epistolar. Para dar um exemplo desse trabalho, Ieda Lebensztayn estudou a correspondência de Graciliano Ramos, que esteve, em sua maior parte, com familiares e amigos íntimos e foi publicada na década de 1970. Ainda, foi necessário reunir, transcrever e comentar toda a correspondência com intelectuais e a comunidade literária. Entre essas cartas, por exemplo, pode-se encontrar correspondência com seu editor francês, Gaston Gallimard, que reproduzimos a seguir: 
Rio de Janeiro, 8 de outubro de 1952

Librairie Gallimard

5, Rue Sébastien - Bottin

Paris (VIIe.)

France

Senhores,

Eu acabo de receber sua carta do $1^{\circ}$ de outubro e dois exemplares do contrato relativo à publicação de meu livro Infância, tradução do Sr. Gogenheim. Eu aceito as condições propostas e eu envio, seguindo a sua recomendação, o contrato já assinado pelo Sr. Gallimard.

Uma pequena modificação. Senhores, o contrato diz: "Rua do Curvidor, 110, Buenos Aires, Argentina”. Não está correto. Eis aqui o endereço verdadeiro: "Rua do Ouvidor -11- Rio de Janeiro - Brasil”. Não tem importância, naturalmente. Mas [, como nós falamos de negócios, é necessário dizer que] nós não estamos na Argentina [Nós somos brasileiros. Somente]

Recebam, Senhores, toda a minha gratidão,

Atenciosamente,

Graciliano Ramos

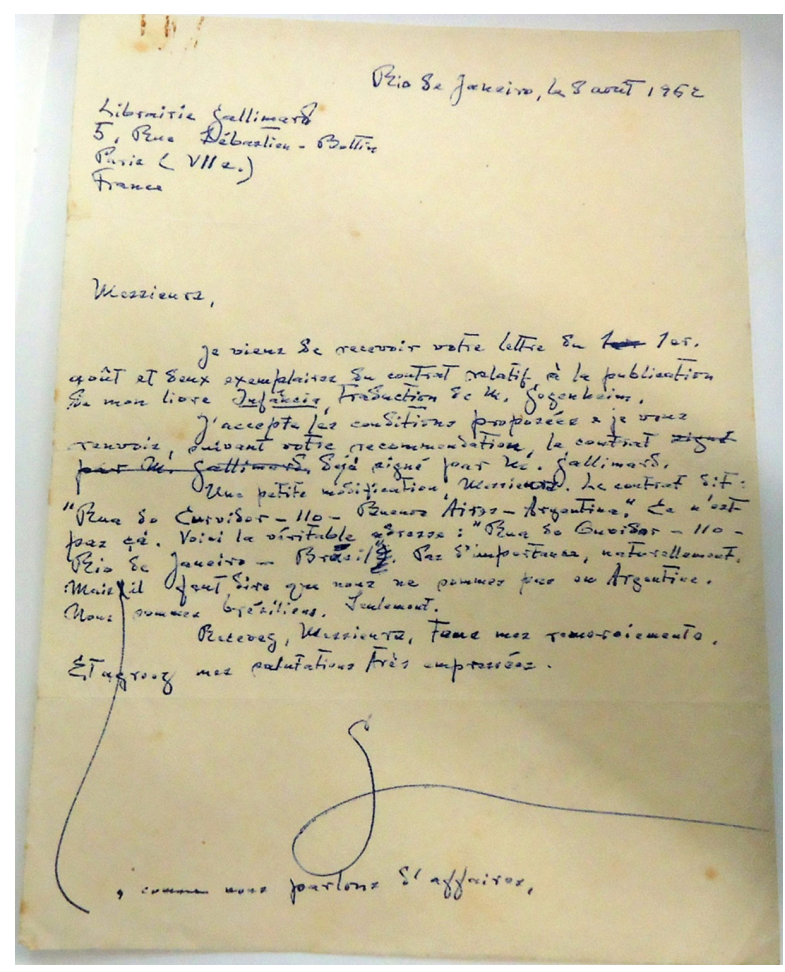

Fonte: Esboço de carta enviada por Mário de Andrade à Livraria Gallimard em 8 de agosto de 1952. 
Podemos observar nesse esboço de carta: 1. o desconhecimento do meio editorial francês em relação ao Brasil; 2. a indignação de Graciliano Ramos presente nas expressões irônicas (como "naturalmente", "como falamos de negócios"); e 3. a decisão de rasurar essas apalavras para não aparecer depreciativo ou superior. Não cabe aqui discutir essas mudanças, mas está claro que eles mostram uma desconfiança em relação aos editores e ao meio literário, o que Ieda Lebensztayn discute amplamente em seu trabalho.

O importante dessa pesquisa é mostrar que o vasto trabalho de coleta e edição proposto por esse grupo é sempre um trabalho genético, pois é principalmente sobre manuscritos de autógrafos que representam problemas específicos em relação aos movimentos criativos.

\section{Um corpus de francês visto de longe}

Forçados a trabalhar em corpus que não são acessiveis do Brasil, esses pesquisadores e seus orientandos conseguiram se desvincular da materialidade do manuscrito e pensá-lo de forma mais ampla, se não mais teórica. Embora cada vez mais próximo dos manuscritos dos grandes autores encontrados no site da Biblioteca Nacional da França ou de sites especializados, o pesquisador brasileiro tem pouco tempo para se dedicar ao estudo dos manuscritos e é forçado a ser criativo.

Philippe Willemart considera o manuscrito não o objeto final da pesquisa, mas um modelo de diálogo com as estruturas do cérebro e as formas mais complexas do universo, baseando-se nas abordagens da psicanálise e das ciências. Em março de 2019, publicou, simultaneamente em português e francês, A escritura na era da indeterminação, pela editora Perspectiva, e pela coleção Modern French Identities, da editora Peter Lang, de Oxford. Ele trabalha atualmente a relação entre a crítica genética e outros saberes, como a psicanálise, a astrofísica, a neurociência e a inteligência artificial (IA), e anuncia um livro que incluirá contribuições de Roberto Zular (crítica genética e antropologia), Yuri Cerqueira dos Anjos (crítica genética e cultura), Edson Pfützenreuter (crítica genética e a filosofia de Flusser) e Celso Loureiro Chaves (crítica genética e música).

Além do trabalho de Philippe Willemart, na Universidade de São Paulo, pesquisadores como Claudia Amigo Pino, Roberto Zular e suas equipes estudam a gênese de forma mais ampla, levando em conta também a circulação e a recepção de manuscritos. Claudia Pino trabalha a partir dos manuscritos do seminário de Roland Barthes, não se limitando ao estudo dos documentos, mas querendo conhecer as características da instituição onde foram produzidos (Ecole des Hautes Études en Sciences Sociales - EHESS) e dos alunos que participaram desses seminários. Além desse trabalho, seus estudantes têm estudado também a circulação da escrita em ambientes editoriais e jornalísticos.

Roberto Zular continuou, no estudo de Paul Valéry (2020), especialmente atento à sua recepção entre os poetas brasileiros. Da reflexão dos seus ensaios que tanto influenciaram os modernistas à publicação dos cadernos decisivos na recepção dos concretos, a crítica genética se colocava entre as práticas de escrita, a reflexão sobre essas práticas e a mudança de sentido operada pelo lugar da escrita em diferentes culturas. Essa preocupação se desdobrou em uma antropologia da escrita que é o seu atual campo de pesquisa, fortemente ligada à relação entre a escrita, o corpo e a voz. 


\section{A CRÍtica Genética em Teresina}

\section{Philippe Willemart}

Após a defesa de sua tese de doutorado em 2009, Márcia Edlene Mauriz Lima, da Universidade do Estado do Piauí (Uespi), criou sua própria equipe de geneticistas voltados principalmente para os manuscritos do estado do Piauí. Com ajuda de alunos de iniciação científica, estabeleceu o catálogo do acervo digitalizado de Renato Castelo Branco e o do acervo de Fontes Ibiapina, de 2009 a 2011. Criou o Núcleo de Estudos em Memória e Acervos (Nema) e organizou simpósios em 2012, 2014, 2016 e 2018, nos quais se reuniam mais de 200 participantes ao redor dos conferencistas convidados e das mesas-redondas com temas relevantes que tratavam da crítica genética e da arquivologia: Criação literária e preservação documental, em 2012; Escritor, escrita e escritura, em 2014; Leitor, leitura e litura, em 2016; Gênese e arquivos, em 2018. Participavam desses simpósios pesquisadores da Uespi, das universidades federais do Piauí, Bahia, Amazonas, Alagoas, Pernambuco, Espírito Santo, Goiás e Rio Grande do Sul, das universidades estaduais e particulares (PUC-SP) de São Paulo e Porto Alegre. A Uespi tornou-se, assim, um polo indispensável e exemplar do desenvolvimento da crítica genética nessa região do país.

\section{A CRÍtICA GENÉTICA EM OUTROS CENTROS UNIVERSITÁRIOS}

\section{Philippe Willemart}

Não posso deixar de mencionar núcleos de estudos genéticos de importância e em atividade situados na Universidade Federal do Espírito Santo (Ufes), com José Cirillo Aparecido (congresso de 2008); na Ufba, com Silvia Anastácio (congresso de 2015); na Universidade Estadual de Londrina (UEL), com Edina Pachini; na Universidade Federal de Alagoas, com Eduardo Calil; na Ufop, com Mônica Gama (congresso de 2017); e na Universidade Federal do Paraná, com Viviane Pereira (congresso de 2019).

Em todas as reuniões anuais da Associação Nacional de Pós-Graduação em Letras e Linguística (Anpoll), consta um grupo de trabalho em critica genética atualmente dirigido por Carla Cavalcanti e Silva, da Universidade Estadual Paulista "Júlio de Mesquita Filho" (Unesp) de Araraquara, e Mônica Gama, da Ufop.

Comparando esse panorama da crítica genética no Brasil com o quadro levantado em 2008, constatamos uma ligeira mudança dos estudos de gênese no século XXI. Embora ainda fortemente centralizados no estudo de manuscritos ou de esboços de escritores e artistas na maioria dos centros de pesquisa, os estudos de gênese se estendem a todas as atividades humanas que implicam processos de criação e documentos de processo. Essa ampliação do objeto da pesquisa indica uma tendência que não era perceptível na sua implantação em 1985, tendência que mostra a inserção cada vez maior e necessária na sociedade do século XXI da internet, da inteligência artificial e das descobertas espaciais.

\section{DiRections OF Genetic CRITICISM IN BRAZIL}

Abstract: The article, written in collaboration with several members of the Association of Researchers in Genetic Criticism (APCG), outlines the current 
panorama of genesis studies in Brazil and notes that the scope of the object of study is no longer limited to the study of the manuscript or the artists' sketches, but that it engages with any human activity that implies processes of creation or process documents.

Keywords: APCG. Creation processes. Process document. Genetic criticism. Arts.

\section{REFERÊNCIAS}

ASSOCIAÇÃO DOS PESQUISADORES EM CRÍTICA GENÉTICA (APCG). XIII Congresso Internacional da APCG - Ouro Preto. 2017. Disponivel em: https:// congressoapcg2017.wordpress.com/2017/03/30/primeiro-post-do-blog/. Acesso em: nov. 2020.

ASSOCIAÇÃO DOS PESQUISADORES EM CRÍTICA GENÉTICA (APCG). XIV Congresso Internacional da APCG - Curitiba. 2019. Disponivel em: https://doity.com. br/congressoapcg/. Acesso em: nov. 2020.

CEIA, C. (ed.). E-dicionário de termos literários. 2010. Disponivel em: https://edtl. fcsh.unl.ptmigo. Acesso em: nov. 2020.

FLUSSER, V. Filosofia da caixa preta. São Paulo: É Realizações, 1983.

GAMALLO, P. et al. LinguaKit: a big data-based multilingual tool for linguistic analysis and information extraction. In: INTERNATIONAL CONFERENCE ON SOCIAL NETWORKS ANALYSIS, MANAGEMENT AND SECURITY (SNAMS), 5. 2018, Valencia. Anais [...]. Valencia: IEEE, 2018. p. 239-244. Disponivel em: https://ieeexplore.ieee.org/document/8554689/. Acesso em: 4 dez. 2020.

LIMA, M. E. M. O inacabamento do acabado: a reescrita de Teodoro Bicanca, de Renato Castelo Branco. Vinhedo: Horizonte, 2016.

LOEWENSTAMM, Kert, O hebraista no trono do Brasil. O imperador D. Pedro II, São Paulo, ed.Centauro, 2002

MORAES, M. A. Orgulho de jamais aconselhar: a epistolografia de Mário de Andrade. São Paulo: Edusp: Fapesp, 2007.

MORAES, M. A. Câmara Cascudo e Mário de Andrade: cartas, 1924-1944. São Paulo: Global, 2010. v. 1.

NÚCLEO DE ESTUDOS DE PROCESSOS CRIATIVOS (Nuproc). Edições genéticas digitais. Hitopadesa. 2020. Disponivel em: http://www.nuproc.cce.ufsc.br/. Acesso em: 14 abr. 2021.

PINO, C. A. (org.). Criação em debate. São Paulo: Humanitas, 2004.

PINO, C. A.; ZULAR, R. Escrever sobre escrever. uma introdução crítica à crítica genética. São Paulo: Martins Fontes, 2007.

PINO, C. C. A. Roland Barthes: a aventura do romance. Rio de Janeiro: 7 Letras, 2015.

PINO, C. C. A. Genèse d'une critique magique : les grands projets de Roland Barthes dans les séminaires de l'EHESS. In: BERTRAND, J.-P. (org.). Roland Barthes: continuités. Paris: Christian Bourgois, 2017. v. 1.

ROMANELLI, S. (org.). Compêndio de crítica genética: América Latina. Vinhedo: Horizonte, 2019. 
RUMOS ITAÚ CULTURAL. Plataforma Aisthesis. Sobre. 2015. Disponivel em: https://plataformaisthesis.wordpress.com/sobre/. Acesso em: 14 abr. 2021.

SALlES, C. A. Redes da criação: construção da obra de arte. 2. ed. Vinhedo: Editora Horizonte, 2008.

SALlES, C. A. Gesto inacabado: processo de criação artística. 5. ed. São Paulo: Intermeios, 2011.

SAlleS, C. A. Processos de criação em grupo: diálogos. São Paulo: Estação das Letras e Cores, 2017

VALÉRY, P. Feitiços: (charmes). Tradução e estudo Roberto Zular e Álvaro Faleiros. Edição bilíngue. São Paulo: Iluminuras, 2020.

WILLEMART, P. A filologia, a crítica genética e a interpretação do texto. In: WILLEMART, P. Bastidores da criação literária. São Paulo: Iluminuras, 1999. WILLEMART, P. Os processos de criação na escritura, na arte e na psicanálise. São Paulo: Perspectiva, 2009.

WILLEMART, P. Psicanálise e teoria literária: o tempo lógico e as rodas da escritura e da leitura. São Paulo: Perspectiva, 2014.

WILlEMART, P. A escritura na era do indeterminismo. São Paulo: Perspectiva, 2019.

WILLEMART, P. Critique génétique et astrophysique: le hors-temps proustien et la physique depuis Einstein, Marcel Proust aujourd'hui. Leiden-Boston: Brill/ Rodopi, 2020.

ZULAR, R. Criação em processo. São Paulo: Iluminuras, 2002. 